\title{
Mecanismos morfossintáticos em línguas indígenas faladas no MS
}

\author{
Morphosyntactic mechanisms in indigenous languages spoken in MS \\ Valéria Faria Cardoso ${ }^{1}$ \\ Universidade do Estado de Mato Grosso
}

\begin{abstract}
- RESUMO: Neste texto são descritos alguns mecanismos morfossintáticos que estão presentes em línguas indígenas faladas no estado de Mato Grosso do Sul (MS). Abordam-se aqui temas tais como classificadores, evidencialidade, sistema de numeração, aplicativos e alinhamento. Tem-se que tais mecanismos morfossintáticos são tidos como fenômenos linguísticos que vêm merecendo a atenção de estudiosos da linguagem humana por apresentarem dados inusuais para teorias linguísticas modernas, ou ainda, àquelas que fixam seus pressupostos teóricos apenas em dados de línguas indo-europeias. $\mathrm{O}$ artigo não distingue nenhuma abordagem teórica em particular mas procura pôr em relevo as pesquisas em línguas indígenas que tenham cunho tipológico-funcional (DIXON, 1994; COMRIE, 1989; PAYNE, 1997; GIVON, 1984).
\end{abstract}

- PALAVRAS-CHAVE: Tipologia linguística. Línguas indígenas. Morfossintaxe.

- ABSTRACT: This text describes some morphosyntactic mechanisms that are present in indigenous languages spoken in the state of Mato Grosso do Sul (MS). Topics such as classifiers, evidentiality, number system, applications and alignment are covered here. These morphosyntactic mechanisms are seen as linguistic phenomena that have come to the attention of scholars of human language because they present unusual data for modern linguistic theories, or those that fix their theoretical presuppositions only on data from IndoEuropean languages. The article does not distinguish any theoretical approach in particular but highlights the research in indigenous languages that has a typological-functional character (DIXON, 1994; COMRIE, 1989; PAYNE, 1997; GIVON, 1984).

- KEYWORDS: Linguistic typology. Indigenous languages. Morphosyntactic.

\section{Introdução}

Há mais de 500 anos, desde que se deu o início da colonização das Américas, as línguas ameríndias (nativas) coexistem espacialmente com línguas europeias, configurando, assim, uma situação de contato de línguas (APPEL; MUYSKEN, 2005:58). No início da colonização portuguesa, existiam mais de mil povos indígenas no Brasil contando com uma população entre dois e quatro milhões e que, atualmente, é de apenas oitocentos e dezessete mil indígenas (IBGE, 2010) ${ }^{2}$. A estimativa referente às línguas que eram faladas por esses povos gira em torno de 1.200. Atualmente, no Brasil, sobrevivem 180 destas línguas. Entretanto, é sabido que dados sobre o número de línguas variam muito e que o número 180 poder vir a ser algo em torno de 150 línguas indígenas (CORBERA MORI, 2012).

Não obstante, considerando cenário dos países da América do Sul, é no Brasil em que se encontra a maior diversidade linguística e cultural ameríndia. E em se

\footnotetext{
${ }^{1}$ Doutora em Linguística pela UNICAMP. valeria.cardoso@ unemat.br

${ }^{2}$ Cf. site: https://indigenas.ibge.gov.br/mapas-indigenas-2. Acesso em 25/09/2017.
} 
tratando da diversidade linguística e cultural no estado de Mato Grosso do Sul (MS) ${ }^{3}$, tem-se que essa é bem representativa já que conta com línguas dos dois tronco linguísticos: o tronco tupi com a língua guarani (kaiowá e nhandewa) e o tronco macrojê com a língua guató, além de outras quatro famílias linguísticas distintas: a família guaicuru com a língua kadiwéu, a família aruak com as línguas terena e kinikinau e a família zamuco com a língua chamacoco. A língua dos Atikum foi extinta e não classificada ${ }^{4}$.

Além do aspecto ligado à genealogia das línguas indígenas faladas atualmente no MS corroborar com a ideia do que seja genuinamente a diversidade linguística que habita esse estado, aspectos estritamente linguísticos refletem a ocorrência de diversos fenômenos que vem merecendo a atenção de estudiosos da linguagem por apresentarem dados inusuais para teorias linguísticas modernas, ou ainda, àquelas que fixam seus pressupostos teóricos apenas em dados de línguas indo-europeias. E, vem a ser a partir destes aspectos especificamente linguísticos que, neste trabalho, tratamos de mecanismos morfossintáticos descritos para as línguas das comunidades ditas originárias dessa região (Guarani, Terena, Kinikinau, Kadiwéu, Guató e Ofayé).

\section{Dos mecanismos morfossintáticos}

Os processos morfossintáticos aqui descritos e analisados são: o sistema de numeração em guató, a evidencialidade em terena, o traço suprassegmental [+ NASAL] como marca de pessoa e número em kinikinau, os classificadores em ofayé, o alinhamento em guarani kaiowá e os aplicativos em kadiwéu.

$\mathrm{O}$ artigo não distingue nenhuma abordagem teórica em particular mas procura pôr em relevo as pesquisas em línguas indígenas que tenham cunho tipológico-funcional (Dixon 1994, Comrie 1989, Payne 1997, Givon 1984). Pesa-se, ainda, para o fato de que os mecanismos descritos e ilustrados aqui são provenientes de estudos relevantes das línguas indígenas brasileiras (PALÁCIO, 2004; NASCIMENTO, 2012; SOUZA, 2008; GUDSCHINSKY, 1974; SANDALO, 2012; CARDOSO, 2015).

\section{Sistema de numeração do guató (guató)}

Os sistemas de numeração de línguas ameríndias tem recebido certa atenção de estudiosos da linguagem por terem limites superiores baixos em comparação com os sistemas de numeração de línguas de outras partes do mundo. Várias línguas amazônicas parecem carecer completamente de números se entendermos que o termo usado para "um" pode também significar "pequena quantidade"; "dois" significar "uns poucos" e a quantidade maior que dois ou três pode ser descritas simplesmente por "vários" ou "muitos". Entre tais línguas, contam-se o krenak (macro-jê), o matsés (pano) e canela-krahô) (EPPS \& SALANOVA 2012:11).

Há também várias línguas ameríndias que possuem conjuntos um pouco maiores de números (ultrapassando três ou cinco) que em sua maioria são expressos por palavras etimologicamente transparentes, e baseiam-se normalmente em palavras para

\footnotetext{
${ }^{3}$ A descrição de mecanismos linguísticos típicos de línguas indígenas faladas no estado de Mato Grosso do Sul atende a uma solicitação de tratamento temático feito pelos coordenadores do II ENSAD - Encontro Nacional em Semântica e Análise do Discurso realizado pela UEMS/NEAD-Campo Grande.

${ }^{4}$ Das 231 etnias existentes no Brasil, nove delas vivem no estado de Mato Grosso do Sul (MS). Seis são tidas como originárias desta região: Guarani (Kaiowá e Nhandewa), Terena, Kinikinau, Kadiwéu, Guató e Ofayé, e três delas têm origem em outras regiões: Atikum - originário do estado de Pernambuco (outro da Bahia), Chamacoco - originários do Paraguai e Bolívia e Kamba - originários da Bolívia.
} 
os dedos das mãos e dos pés, por exemplo, "seis" para expressar "um outro dedo levantado" ou "outro polegar"; ou ainda, são palavras derivadas de partes do corpo, como "dois" expresso por "braços" ou "olhos".

A língua Guató, classificada geneticamente no tronco Macro-Jê por Rodrigues (1994), possui sistema numeral de base quinária, até o número "vinte", e decimal, para números acima de "vinte", tendo assim valores representativos muito altos, o que a diferencia da maioria das línguas ameríndias brasileiras que, como exposto acima, possuem sistemas de numeração de limites superiores baixos.

Para Palácio (1996 e 2004), os números de um a quatro, em Guató, são constituídos por partículas: èéne 'um', dúni 'dois', èúmu 'três', rékai 'quatro', além de dois nomes que participam da formação dos números: rá 'mão' e bo 'pé', que geralmente aparecem flexionadas na terceira pessoa do singular: $i$-rá (3-mão) 'mão de alguém', $i$-bo (3-pé) 'pé de alguém'. No que segue, ilustramos os numerais de 1 a 20 em guató.

\begin{tabular}{llllllll}
\multicolumn{2}{l}{ guató (Palácio 2004) } & & & & \\
$\mathbf{1}$ & èéne & $\mathbf{6}$ & èéne kaéka i-rá & $\mathbf{1 1}$ & èéne i-bo & $\mathbf{1 6}$ & èéne deèúa \\
$\mathbf{2}$ & dúni & $\mathbf{7}$ & dúni kaéka i-rá & $\mathbf{1 2}$ & dúni i-bo & $\mathbf{1 7}$ & dúni deèúa \\
$\mathbf{3}$ & èúmu & $\mathbf{8}$ & èúmu kaéka i-rá & $\mathbf{1 3}$ & èúmu i-bo & $\mathbf{1 8}$ & èúmu deèúa \\
$\mathbf{4}$ & rékai & $\mathbf{9}$ & rékai kaéka i-rá & $\mathbf{1 4}$ & rékai i-bo & $\mathbf{1 9}$ & rékai deèúa \\
$\mathbf{5}$ & tóhe-rá & $\mathbf{1 0}$ & kínu i-rá & $\mathbf{1 5}$ & kávi-bo & $\mathbf{2 0}$ & kwávivĩ-bo
\end{tabular}

Palácio descreve dezessete partículas para numerais em guató, doze das quais são formas livres:

i) quatro formas indicam os números de 1 - 4: èéne, dúni, èúmu, rékai;

ii) uma forma participa da formação dos números de 6 - 9: kaéka;

iii) outra forma indicam os números de 16 - 19: deèúa;

iv) as palavras que constituem o quinto elemento de cada conjunto até o número 20 são palavras: tóherá 'cinco', kínu i-rá 'dez', kávibs 'quinze' e kwávivibo 'vinte', e

v) as palavras gwátehe para 'centena' e édé para 'milhar'.

Considerando os limites superiores baixos, bem como os altos, para os sistema de numeração das línguas ameríndias brasileiras, entende-se que essas línguas proporcionam evidencias interessante sobre o desenvolvimento histórico dos sistemas de numeração. Uma das evidências é de que a numeração não é uma propriedade universal, mas sim uma criação motivada culturalmente.

\section{Evidencialidade em terena (aruak)}

Todas as línguas possuem meios para qualificar evidencialmente um enunciado. Algumas línguas contam com mecanismos para codificar morfossintaticamente a evidência de que o falante dispõe quando enuncia algo. Tais mecanismos são conhecidos como evidenciais e já foram descritos para línguas das famílias aruak, tupi, pano, nadahup, nambikwara.

$\mathrm{Na}$ língua terena, a evidencialidade é indicada por meio do sufixo $\{\mathrm{hi}\}$, um morfema verbal evidencial indireto (morfema=diz que). Em tal contexto, este afixo é usado para indicar que o falante não presenciou os fatos, vindo a ter conhecimento dos mesmos por meio de terceiros (NASCIMENTO, 2012, p. 77). 
terena (NASCIMENTO, 2012)

\begin{tabular}{|c|c|c|c|}
\hline $\begin{array}{l}\text { ape-1 } \\
\text { exist }\end{array}$ & EVD & $\begin{array}{lr}\text { ayui } & \text { ne h } \\
\text { festa } & \text { DET } \\
& \text { "di }\end{array}$ & $\begin{array}{l}\text { peno hiko mekuke ya vanukeke. } \\
\text { muito antigamente LOC céu } \\
\text { m que antigamente, houve uma festa da bicharada no céu" }\end{array}$ \\
\hline yane & $\emptyset$-sil & o-ne-hi & ne varututu \\
\hline $\mathrm{MD}$ & $3-\mathrm{ch}$ & gar-PERF-EVD & DET urubu \\
\hline
\end{tabular}

"então dizem que o urubu chegou..."

Uma outra língua da família aruak, o tariana (falada na Amazônia), por seu contato com a língua tucano (tucano), passou a exibir quatro categorias de evidencialidade: visual, não- visual, inferida e relatada:

\begin{tabular}{|c|c|c|}
\hline Ceci & $\mathrm{t}$ (jinu-nuku & du-kwisa-ka \\
\hline Cecília & cachorro-TOP & $\begin{array}{l}\text { 3SGF-xingar-P.REC-VIS } \\
\qquad \text { 'Cecília xingou o cachorro' (eu vi isso) }\end{array}$ \\
\hline Ceci & t finu-nuku & du-kwisa-mahka \\
\hline Cecília & cachorro-TOP & $\begin{array}{l}\text { 3SGF-xingar-P.REC-NVIS } \\
\text { 'Cecília xingou o cachorro' (eu ouvi fazê-lo) }\end{array}$ \\
\hline Ceci & t $\int i n u-n u k u$ & du-kwisa-sika \\
\hline Cecília & cachorro-TOP & 3SGF-xingar-P.REC-INFER \\
\hline
\end{tabular}

'Cecília xingou o cachorro' (eu infiro pelo comportamento do cachorro)

Ceci t tinu-nuku du-kwisa-pidaka

Cecília cachorro-TOP 3SGF-xingar-P.REC-REL

‘Cecília xingou o cachorro' (alguém contou-me)

Infere-se, assim, que o acentuado valor discursivo próprio à evidencialidade faz com que as línguas estejam propensas ao empréstimo dessa categoria estando as mesmas em situação de contato linguísticos.

\section{O traço suprassegmental [+ NASAL] como marca de pessoa e número em kinikinau (aruak)}

A morfologia verbal kinikinau ocorre com marcadores de pessoa, número e caso (configuracionalmente) manifestos por processos morfofonológicos que caracterizam as propriedades de $1^{\mathrm{a}}$. e $2^{\mathrm{a}}$. pessoas do singular.

Aqui tratamos especificamente da marcação da $1^{\mathrm{a}}$. pessoa do singular que ocorre junto à morfologia verbal kinikinau e é manifesta morfofonologicamente pelo traço [+ NASAL].

As formas verbais iniciadas por obstruentes recebem influência do traço suprassegmental [+ NASAL], sonorizando-se e pré-nasalizando-se.

Formas verbais com obstruentes iniciais em kinikinau (SOUZA, 2008, p. 103)

Forma não-marcada $\left(3^{\mathrm{a}} \cdot \mathrm{p} . \mathrm{sg}\right)$

pore $-\mathrm{x}-\mathrm{O}-\mathrm{a}-\mathrm{ti}$ dar -CT -IND -OBJ -IMPERF

(ele) está dando-o
Forma marcada ( $1^{\text {a }}$. p. sg.)

mbore - $\mathrm{x}$-o -a ti

1Sg.dar -CT -IND -OBJ -IMPERF

eu estou dando-o 
tetu $-\mathrm{k}-\mathrm{o}-\mathrm{a}-\mathrm{ti}$

cortar -CT -IND -OBJ -IMPERF

(ele) está cortando-o

humi $-\mathrm{k}-\mathrm{o}-\mathrm{ti}$

assoviar -CT -IND -IMPERF

(ele) está assoviando ndetu $-\mathrm{k}-\mathrm{o}-\mathrm{a}-\mathrm{ti}$

1Sg,cortar - CT -IND -OBJ -IMPERF

eu estou cortando-o

nzumi -k -o -ti

1Sg.assoviar -CT -IND -IMPERF

eu estou assoviando

As formas verbais sem obstruentes iniciais em sua constituição fonológica também recebem influência do traço suprassegmental [+ NASAL] ao espalhar nasalidade para todas as vogais e semivogais da esquerda para a direita do verbo kinikinau.

Formas verbais sem obstruentes iniciais em kinikinau (SOUZA, 2008)

Forma não-marcada ( $3^{\mathrm{a}}$. p. sg.)

yonôti

Forma marcada ( $1^{\mathrm{a}}$. p. sg.)

andar

(ele) está andando

ỹõnõã - ก

1Sg.andar -PONT

eu andei

omo - ne

õmõ -nẽ

trazer -PONT

(ele) trouxe

1Sg.trazer -PONT

eu trouxe

Em geral, as mesmas regras que marcam as pessoas verbais em kinikinau operam junto as formas nominais genitivas nesta língua. Desse modo, o traço suprassegmental [+ NASAL] indica a posse nominal de $1^{a}$. pessoa do singular.

\section{Formas nominais kinikinau}

Forma não-marcada

ûke

hêwe

ha'a
Forma marcada

ûnge 'meu olho'

njêwe 'meu pé'

nza'a 'meu pai'

\section{Classificadores em ofayé (ofayé)}

Algumas línguas naturais exigem que nomes genitivos e/ou modificados por numerais sejam acompanhados por formas organizadoras selecionadas pelos nomes na medida em que os mesmos se refiram a seres humanos, animais, partes do corpo etc. Tais formas são tidas como classificadores.

Para Gudschinsky, a língua ofayé possui nominais com morfemas que "parece ser um formador de radical especial ou classificador" (1974, p.209).

A autora descreve o afixo $\{\mathrm{ky}$. $\}$ como um classificador para coisas redondas e os afixos $\{$ wo. $\} \sim\{$ w. $\} \sim\{$ o. $\}$ para nomes de animais.

ofayé (Gudschinsky, 1974, 209)

\section{$\{k y$.$\} CL=redondo$}

$-\mathbf{k y}-{ }^{\prime} \mathrm{t} \varepsilon: \mathrm{q}$

-CL-cabeça $-\mathbf{k y}-^{\prime} t \varepsilon j(q)$

-CL-olho 
$\tilde{y}-\mathbf{k y}$-'teq

3a.-CL-ovo

\section{\{wo. $\sim$ w. $\sim$ o. $\}$ CL=animais}

'wo-'jih

CL-paca

w-'aky'te:h

CL-lagarto

$$
\begin{aligned}
& \text { w-'ykší kõ:raq } \\
& \text { CL-onça } \\
& \text { o-'hy:r } \\
& \text { CL-coruja }
\end{aligned}
$$

Gudschinsky descreve ainda três séries de afixos indicadores de posse nominal na língua ofayé, sendo uma série para nomes alienáveis e duas outras para nomes inalienáveis. Sugerimos que a distinção entre essas duas últimas séries de nominais inalienáveis decorra de uma função classificadora genitiva nesta língua.

i. Classificador genitivo da série \{ašy. šy.\} indicador de partes com traços do tipo + extremo + incisivo + alongado

ofayé (Gudschinsky 1974:197)

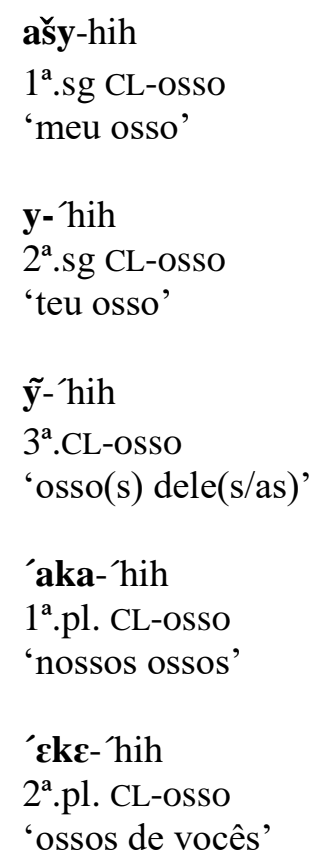

A observação dos dados ofayé descritos por Gudschinsky (1974), nos permite inferir que nominais inalienáveis marcados pela série $\{$ ašy. šy $\}$ sejam classificadores genitivos que categorizam partes que podem estar remetendo a traços do tipo: + extremo + incisivo + alongado. Isso, de modo consonântico, com os seguintes nominais inalienáveis da língua ofayé: cabeça, pé, cabelo, ombro, pé, pele etc.

ii. Classificadores genitivos da série \{jīj. jĩ.\} indicador de partes com traços do tipo + extremo + incisivo - alongado

categorizam partes com traços + extremo + pontiagudo + comprido 
ofayé (Gudschinsky 1974:195)

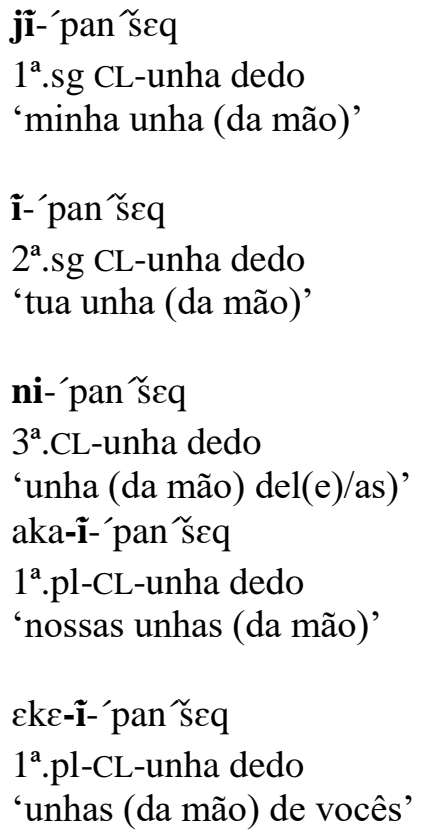

Os nominais inalienáveis marcados pela série $\{$ jĩj. jĩ. $\}$ também são tidos como classificadores. Neste caso, supomos que os classificadores categorizem nominais inalienáveis ofayé que façam referência a partes + extrema + incisiva - alongada, em conformidade com os seguintes nomes agrupados por essa série: unha, nariz, orelha etc. Vale ainda mencionar que foi possível recuperar o significado primitivo da forma [jĩj. jĩ.\} com função classificadora que, em ofayé, designa 'mão'.

\section{Alinhamento em guarani kaiowá (tupi-guarani)}

"Relação gramatical" ou "alinhamento" diz respeito à relação entre o verbo e as funções gramaticais de seus argumentos. Segundo Dixon (1994), os termos ergativo e ergatividade e acusativo e acusatividade podem ser usados para descreverem o caminho em que funções sintáticas dos argumentos predicativos são marcadas em sentenças transitivas e intransitivas, isto é, se $\mathrm{S}$ é marcado num mesmo caminho que $\mathrm{O}$ e diferentemente de $\mathrm{A}$ (num arranjo ergativo), ou se $\mathrm{S}$ é marcado no mesmo caminho que A e diferetnemente de $\mathrm{O}$ (num arranjo acusativo). Dixon trata este tipo de descrição como ergatividadelacusatividade morfológica ou intra-clausal. Comrie (1981) adverte sobre a existência de línguas que "misturam" dos dois principais padrões gramaticais (o ergativo e o acusativo). Dixon (1994) descreve essa "mistura" de termos de Sistemas de Cisões.

Segundo Corbera Mori (2016:204), baseando-se na linha tipológica de alinhamento sintático proposta por Dixon (1994), Cardoso analisa o Kaiowá como uma língua de intransitividade cindida ou Split-S, ou seja, o argumento S comporta-se como o argumento A de uma sentença com verbo transitivo, rotulado como Sa, e é codificada pelos prefixos marcadores de pessoa da série I. Quando o argumento $\mathrm{S}$ se identifica de mesma forma que o argumento interno $\mathrm{O}$ de um verbo transitivo, este é rotulado por So e é codificado pelos clíticos pronominais da série II. 
kaiowá (CARDOSO, 2015, p. 211)

Quadro 1. Séries de marcadores de pessoa e número

\begin{tabular}{|c|c|c|}
\hline Pessoa/ Número & $\begin{array}{c}\text { Prefixos da Série I } \\
\text { (A e Sa) }\end{array}$ & $\begin{array}{c}\text { Clíticos da Série II } \\
\text { (O e So) }\end{array}$ \\
\hline $1 \mathrm{sg}$ & $\{$ a. & $\{$ che. $\}$ \\
\hline $2 \mathrm{sg}$ & $\{$ re. $\}$ & $\{$ nde. $\sim$ nẽ. $\}$ \\
\hline $1 \mathrm{pl}(\mathrm{incl})$ & $\{$ ja. & $\{$ nhande. $\sim$ nhanẽ. $\}$ \\
\hline $1 \mathrm{pl}(\mathrm{excl})$ & $\{$ ro. & $\{$ ore. $\}$ \\
\hline $2 \mathrm{pl}$ & $\{$ pe. & $\{$ pende. $\sim$ penẽ. $\}$ \\
\hline 3 & $\{$ o. & $\{$ i. $\sim$ h. $\}$ \\
\hline
\end{tabular}

prefixo da série I - marcando (A)

[Se ainũ'pa i $\left.\int u^{\prime} p e\right]$

< che a- i- nupã i-chupe >

eu 1a.sg(A)-dir-bater 3a./rel-Acus

'eu bato $[\mathrm{n}](\mathrm{ele})$ '

prefixo da série I - marcando (Sa)

[ e ãygwãhẽmã]

< che a- gwahẽ-mã >

eu 1a.sg(Sa)-chegar-PONT

'eu já cheguei'

prefixo da série II - marcando (O)

[de Sere' $\int a$ ave]

$<$ nde che $=$ r-echa ave $>$

você $1 \mathrm{a} . \operatorname{sg}(\mathrm{O})=$ inv-ver PTC

'você me vê também'

prefixo da série II - marcando (So)

[Se Sekì'ra ete'rej]

$<$ che che= kyra eterey >

eu 1a.sg(So)=gordo INTES

'eu engordei muito mesmo'

Considerando apenas os prefixos das séries I e II da língua kaiowá como marcadores de pessoa em verbos independentes num arranjo entre os participantes (A), $(\mathrm{O}),(\mathrm{Sa})$ e (So), analisa-se que (Sa) de verbos intransitivos marcados com a série I possui correferência no mesmo caminho que (A) e (So) de verbos intransitivos marcados com a série II, correferem-se a (O) de verbos transitivos, podemos, então, situar as regras de correferência cruzada operando sobre o Sistema Ativo/Inativo ou Split-S, em verbos independentes da língua guarani kaiowá.

\section{Aplicativos em kadiwéu (guaicuru)}

Kadiwéu é uma língua da família guaikurú que possui tipologia morfológica de línguas polissintéticas ${ }^{5}$. A elaboração morfológica do verbo kadiwéu exibe marcação afixal de argumentos múltiplos, não constando nem mesmo adposições livres, uma vez

\footnotetext{
${ }^{5}$ Entende-se por língua polissintética clássica aquela que é mais que ordinariamente sintética, com a elaboração de uma palavra extrema. Conceitos que nunca pensaríamos em tratar de uma maneira subordinada são simbolizados por afixos derivacionais ou mudanças simbólicas no elemento radical, enquanto noções mais abstratas, incluindo relações sintáticas, podem também ser transmitidas pela palavra. (Sapir 1933:158).
} 
que a língua conta com um complexo sistema de aplicativos e de direcionais na morfologia verbal. (SANDALO, 2012; NEVINS \& SANDALO, 2011).

O kadiwéu é uma língua ergativa cujo objeto do verbo transitivo é marcado no mesmo caminho em que se marca o sujeito inacusativo, já o sujeito inergativo é marcado no mesmo caminho em que se marca o sujeito do verbo transitivo. Sendo o argumento de 3 a. pessoa, a língua mostrasse num caminho cindido, tripartido.

Em kadiwéu, as propriedades morfossintáticas da categoria de caso são afixadas à morfologia verbal por séries de afixos também marcadores de pessoa e número. Observemos o verbo transitivo exemplificado por meio do verbo emaan 'amar':

kadiwéu (Nevins \& Sandalo 2011:6)

verbo transitivo com sujeito marcado

(ee) j-emaa (naGada)

(I) $1 \mathrm{Ag}$ - love (her)

"I love her"

\section{verbo transitivo com objeto marcado}

(naGada) (ee) i- d:- emaa

(She) (I) 1OBJ- inv- love

"She loves me"

Em construções bitransitivas, em que ocorre o objeto direto e o objeto indireto, ambos são marcados pelas séries de afixos de pessoa e número. Quanto ao objeto indireto, este não conta com adposições livres, sendo marcado pelo morfema aplicativo que se sufixa à morfologia verbal, seguido da marca de pessoa e número.

\section{verbo bitransitivo com marca morfológica para o aplicativo}

j- eloGodi- ta

$1 \mathrm{Ag}$ - tell- Appl

"I tell it to him'

j- eloGodi- ta- Ga- wa

1Ag- tell- Appl- 2Obj- Inv2

"I tell it to you"

Nos dados acima, o morfema \{.ta.\} marca o aplicativo na língua, sendo o mesmo um núcleo que marca um dos objetos nas construções de duplo objetos.

\section{Considerações finais}

O tratamento morfossintático do sistema de numeração em guató, da evidencialidade em terena, da marcação de pessoa e número em kinikinau, dos classificadores em ofayé, do alinhamento em kaiowá e dos aplicativos em kadiwéu decorre numa amostra da riqueza linguística inerente a essas línguas indígenas faladas no MS, a exemplo da diversidade cultural das línguas indígenas brasileiras.

Os mecanismos linguísticos apresentados neste trabalho compõe alguns dos principais temas que vêm merecendo a atenção de estudiosos da linguagem humana por contribuírem para o avanço da teoria linguística. Contudo, o essencial vem a ser 
reconhecer o quão é impossível exagerar o valor dessas línguas enquanto legado cultural de seus povos.

\section{REFERÊNCIAS}

APPEL, René; MUYSKEN, Pieter (1989). Language Contact and Bilingualism. London: Edward Arnaold.

CARDOSO, Valéria Faria (2015). Descrição gramatical do Kaiowá (Guarani). Pontos essenciais. Berlin: Novas edições acadêmicas. Pp. 248.

COMRIE, B. (1989). Language universals e linguistic typology. Chicago: Chicago University Press.

CORBERA MORI, Angel H. (2016). Resenha: Descrição gramatical do Kaiowá (Guarani). Pontos essenciais. In: Liames (UNICAMP), No. 16 v. 1, pp. 201-205.

(2012). Mecanismos morfossintáticos em línguas indígenas brasileiras. In: Souza, Edson R. (org.). Funcionalismo linguístico: análise e descrição. São Paulo: Contexto.

DIXON, R. M. W. (1994). Ergativity. Cambridge: Cambridge University Press.

EPPS, Patience \& SALANOVA, Andrés P. (2012). A linguística amazônica hoje. In: Liames (UNICAMP), no. 12, pp. 7-37.

GIVON, T. (1984). Syntax: a functional-typological introduction. Vol. I. Amsterdam/Philadelphia.

GUDSCHINSKY, Sarah C. (1974). Fragmentos de Ofaié: descrição de uma língua extinta. SIL: 03: 177-247.

NASCIMENTO, Gardenia B. N. (2012). Aspectos gramaticais da língua terena. Dissertação (Mestrado) - UFMG.

NEVINS, Andrew \& SANDALO, Filomena (2011). Markedness and morphotactics in Kadiwéu. [+participant] agreement. Morphology 21.2: 351-378.

PALÁCIO, Adair Pimenel. (2004). Alguns aspectos da língua guató. In: Liames (UNICAMP), no. 04, pp. 161-168.

(1996). Sistema numeral em guató. IN: ABRALIN - Boletim da Associação Brasileira de Linguística, no. 19.

PAYNE, T. (1997). Describing morphossyntax: a guide for fiel linguistic. Cambridge: Cambridge University Press.

Rodrigues, A. D. (1994). Línguas brasileiras: para o conhecimento das línguas indígenas. São Paulo: Loyola.

SANDALO, Filomena. (2012). Condição C em Kadiwéw. In: Revista LinguíStica: Revista do Programa de Pós-Graduação em Linguística da Universidade Federal

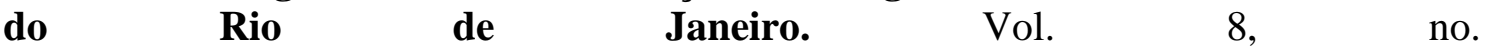
2.[http://www.letras.ufrj.br/poslinguistica/revistalinguistica].

SAPIR, Edward. (1933). Language In: Encyclopaedia of the Social Sciences. New York: 9: 155-169.

SHERZER, Joel (1987). A discourse-centered approach to language and culture. American Anthropologist. 89(2): 295-309. 
SOUZA, I. (2008). Koenukunoe emo’u: A língua dos Kinikinau. Tese (Doutorado), Universidade Estadual de Campinas.

Recebido em: agosto de 2017.

Aprovado em: outubro de 2017.

Como citar este trabalho:

CARDOSO, V. F. Mecanismos morfossintáticos em línguas indígenas faladas no MS. Traços de linguagem, v. 1, n. 2, p. 78-88, 2017.

\begin{abstract}
ABREVIATURAS
$\mathrm{EVD}=$ evidencial, $\mathrm{DET}=$ determinante, $\mathrm{CL}=$ classificador, $\mathrm{LOC}=$ locativo, $\mathrm{MD}=$ marcador discursivo, TOP=tópico, P.REC=passado recente, VIS=visual, NVIS=não visual, INFER=inferida, REL=relatada, $\mathrm{CT}=$ consoante temática, IND=indefinido, $\mathrm{OBJ}=$ objeto, IMPERF=imperfectivo, PERF=perfectivo, PONT=pontual, $\mathrm{sg}=$ singular, $\mathrm{pl}=$ plural, incl $=$ inclusivo, excl.=exclusivo, dir $=$ direta. inv=inversa, $\mathrm{Sa}=$ sujeito intransitivo ativo, $\mathrm{So}=$ sujeito intransitivo inativo, $\mathrm{A}=$ sujeito transitivo, $\mathrm{O}=$ objeto transitivo, Acus=acusativo, PTC=partícula, INTES=intensivo, Ag=Agreement, Appl=application .
\end{abstract}

